\title{
USE OF DIFFERENT CALLS BY TREE SWALLOWS DURING GROUP MOBBING OF PREDATORS
}

PATRICK LEIGHTON, Department of Biology, McGill University, Stewart Biology Building, 1205 Avenue Docteur Penfield, Montreal, QC, H3A 1B1; E-mail: <patrick.leighton@mail.mcgill.ca>

\section{Introduction}

Mobbing is a widespread antipredator behaviour used by parent birds to defend their offspring, and is particularly common in passerines. ${ }^{2}$ It is generally characterised by approaches toward a predator accompanied by stereotyped visual and vocal displays, and mobbing by one individual often draws other birds in the vicinity to mob the same predator, resulting in the formation of a mobbing group. ${ }^{1,5}$ Mobbing may serve to silence offspring, alert relatives to the presence of a predator, signal to the predator that it has been detected, confuse the predator, or cause the predator to leave the area. ${ }^{1}$

Tree Swallows breed in most areas of Saskatchewan, wherever there is an ample source of their main prey, flying insects. Tree

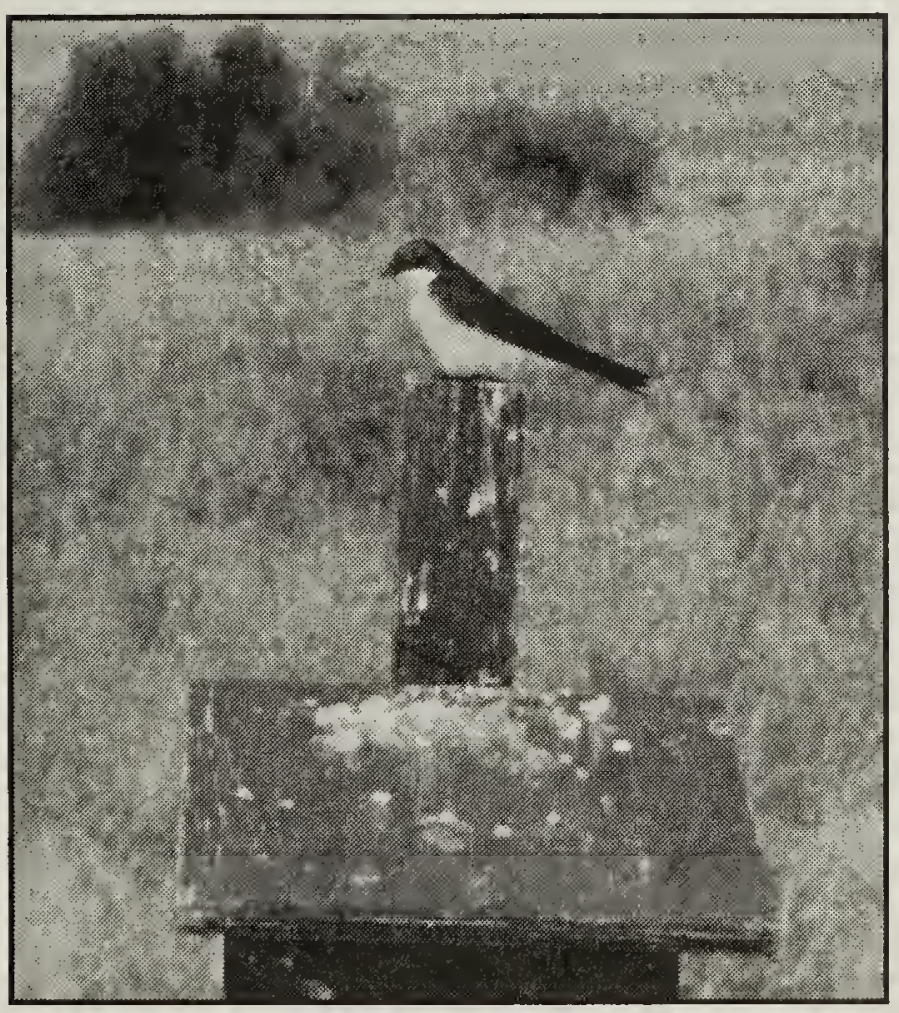

Figure 1. Adult Tree Swallow at nest box, St. Denis National Wildlife Area.

Patrick Leighton
Swallows are cavity nesters and will readily inhabit artificial nest boxes (Fig.1), and thus they are a convenient species for studies of nest defence. ${ }^{6.7}$ While they are not colonial nesters, Tree Swallows mob readily and form large mobbing groups in response to potential predators, circling and diving at the intruder while harassing it with mobbing calls. Several types of call are used during mobbing, however previous publications regarding their function have overlooked differences in the behavioural context of their use..$^{4.7}$ Here I describe the mobbing behaviour of Tree Swallows which were responding to models of potential predators, with particular attention paid to the use of mobbing calls.

\section{Methods}

My research was conducted from May to July, 2001 on the St. Denis National Wildlife Area (NWA), Saskatchewan. The NWA is a section and a half (389 hectares) of land characterized by rolling hills and numerous wetlands which vary in size and permanency. Vegetation is a mixture of native grassland and cropland, interspersed with aspen bluffs. One hundred and forty nest boxes are maintained on the site, mounted on metal poles at $30 \mathrm{~m}$ intervals along trails that traverse the NWA, and most are occupied each year by Tree Swallows.

The mobbing behavior of swallows was studied by presenting artificial mobbing stimuli at an occupied nest box. All tests were conducted during the period when the nest boxes contained nestlings. Three mobbing stimuli were used: a live ferret, a mounted Northern Goshawk, and a hawk-sized box 
$(10 \times 10 \times 30 \mathrm{~cm})$ that served as a control for the presence of a foreign object near the swallow's nest box. Each mobbing trial began with the unveiling of the predator model. The ferret was hidden in an empty nest box placed next to the nest box occupied by swallows, and was unveiled by releasing it down a gangplank onto the roof of the swallow's nest box (Fig.2). The goshawk and the control hawk-sized box were placed on aluminum poles $2 \mathrm{~m}$ from the entrance of the nest box. Each was veiled by a green garbage bag which was then removed to reveal these predator models and begin the mobbing trial. Unveilings were performed from a distance, using monofilament line. Each presentation lasted 3 minutes and was video taped from a distance of $20 \mathrm{~m}$, with additional observations recorded in a field book.

For analysis, I divided each trial into six 30 -second segments. Call rates and dive rates for each segment were calculated from video tapes. I recorded the total number of visible mobbing birds at the end of each 30 s segment in the field. Since there was a short delay before the unveiled predator models were detected, segment 1 was not representative of overall call rates and was therefore excluded from calculations of averages for each trial. The control hawk-sized box elicited zero mobbing response in all trials, and therefore I present only results from the 19 hawk trials and 17 ferret trials.

\section{Results}

Tree Swallows used three main types of call in the context of predator mobbing: the "shriek" call, the "tikking aggression" call, and the "rasping aggression" call, hereafter referred to as shrieks, tiks, and rasps respectively. ${ }^{4}$ Here, I have divided the sequence of events during mobbing into 3 stages to highlight the use of these different mobbing calls; however, mobbing is a continuous process and the stages I describe overlap considerably.

\section{Stage 1. Initiation of Mobbing}

The initial detection of the predator elicited a rapid and persistent repetition of the shriek call by one or more individuals. The shriek call resembles an abrasive scream, a fraction of a second in duration. Shrieks are occasionally given in isolation, but more often in bursts of repeated calls. Bursts typically consisted of a sequence of doublets (shriekshriek, shriek-shriek...), but sometimes also took the form of a continuous series of calls (shriek-shriek-shriek-shriek...).

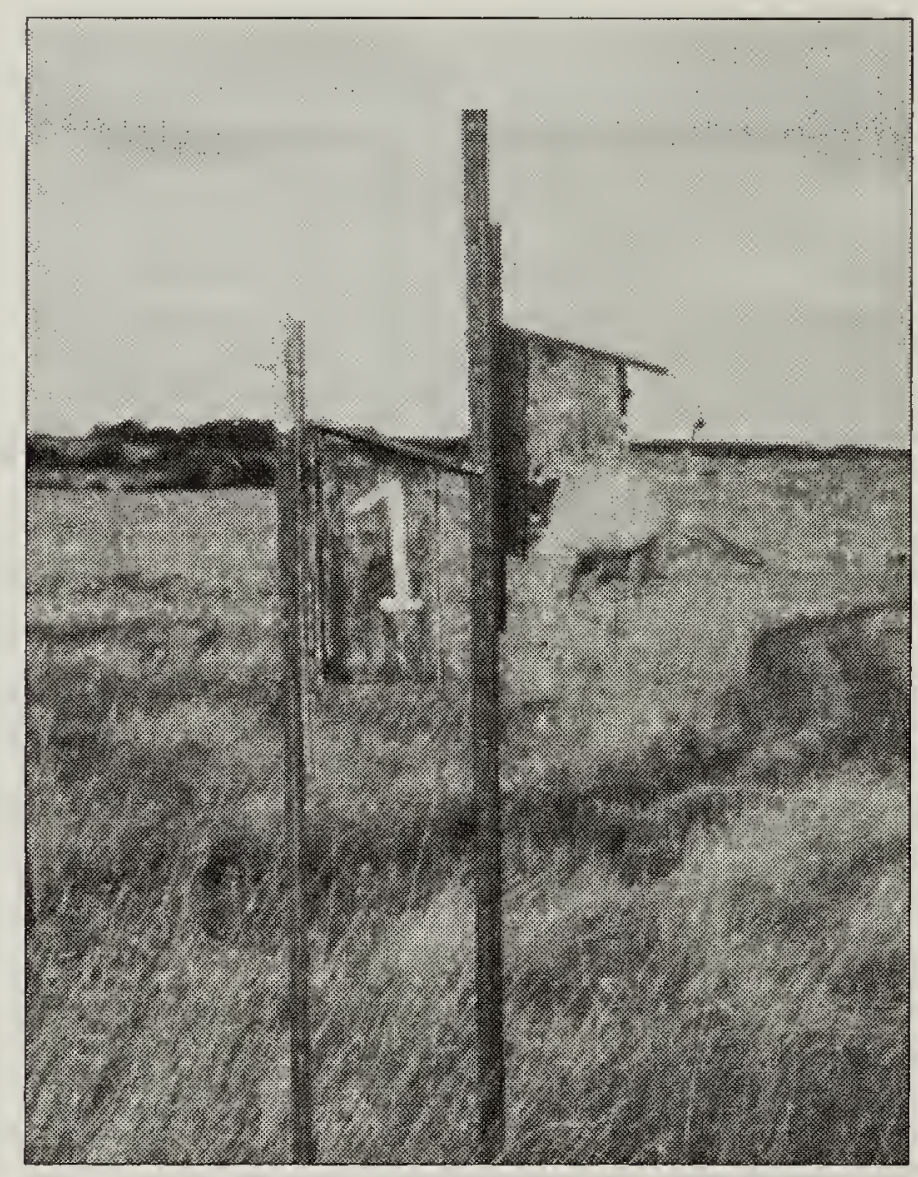

Figure 2. Domestic ferret as mobbing stimulus. Patrick Leighton

During mobbing trials, predators typically were detected within 30 seconds following unveiling of the predator model. The average interval before the first shriek was 15 seconds $(n=36, S D=22)$. Overall call rates were high, with an average of 116.2 calls $/ \mathrm{min}(n=36$, $S D=91.8 \mathrm{calls} / \mathrm{min})$ and ranging up to 336 calls/min (Table 1).

While the form and use of shriek calls was similar among individuals, there was considerable variation in the pitch and quality of calls of different swallows, making individual voices readily distinguishable. The vast majority of shriek calls during a mobbing trial were given by the same individual, and in cases where multiple individuals called, secondary 
callers tended to intercalate their bursts of calling with those of the primary caller, resulting in little acoustic overlap. Previous reports on mobbing by Tree Swallows also note that, for predators near an occupied nest, shriek calling was performed mainly by the parents, in particular the male. ${ }^{6,7}$

\section{Stage 2. Formation of Mobbing Group and Passive Mobbing}

Following the initial shriek calls, mobbing groups assembled rapidly. Swallows foraging in the area arrived within seconds of the initial shriek calls and began to mob passively. Passive mobbing includes both circling the predator and calling, but not diving. Swallows that engaged in passive mobbing tended to limit their calling to short bursts of shriek calls, but also occasionally gave tik calls while circling (see Stage 3, below).

The average number of swallows present in the mobbing group was $5.2(n=36, S D$ $=3.3$ ), but there was considerable variation among trials, and as many as 18 swallows mobbed simultaneously in one instance (Table 1).

\section{Stage 3. Active Mobbing}

Active mobbing consisted of dives toward the predator accompanied by two types of aggression call, tiks and rasps, and usually began once several mobbing swallows were present.

When diving, a circling swallow would alter its flight path to make a sharp, parabolic swoop towards the predator. Dives were directed at the predator's head, and with very few exceptions, were accompanied by a tik or rasp aggression call. Most active mobbing ( $81 \%$ of trials) involved dives that came within $0.5 \mathrm{~m}$ of their target, and very aggressive individuals occasionally came as close as $5 \mathrm{~cm}$. Actual contact with the predator was never observed. The average dive rate was $18.8 \mathrm{dives} / \mathrm{min}(n=36, S D=15.6)$, with a maximum of 78 dives/min (Table 1).
While sonograms of tiks and rasps span similar frequencies, these calls are quite distinct in both form and use. ${ }^{4}$ The tik call consists of 3 to 6 chipping clicks, repeated in quick succession: "tik-tik-tik". The call starts before the bird reaches the bottom of the dive, often spanning the entire swoop, and is also given occasionally while circling. The average tik rate during mobbing trials was 8.7 calls/ $\min (n=36, S D=10.0)$, but ranged as high as 74 calls/min (Table 1 ).

The rasp call is a harsh squawk delivered like a punch at the bottom of the dive as the swallow passes next to the predator's head. It occurs most often during closer, sharper dives and, unlike the tik call, was observed exclusively during diving. The average rasp rate during mobbing trials was 10.4 calls $/ \mathrm{min}$ $(n=36, S D=12.1)$, with a maximum of 50 calls/min (Table 1).

Tiks and rasps were often combined into a continuous aggression call with a series of tiks leading up to a rasp at the bottom of the dive: "tik-tik-tik-RASP." Ten percent of the 1,528 aggression calls I recorded during mobbing trials had both a tik and a rasp component.

\section{Discussion}

The behavioural context in which I recorded shrieks, tiks, and rasps suggests that these three calls may be serving different functions during predator mobbing. Previous studies have shown a relationship between the rate of shriek calling by parent swallows defending their nest and the number of individuals in the resulting mobbing group ${ }^{6.7}$, suggesting that this call may alert other swallows to the presence of a predator in the area and recruit them to mob. The rapid assembly of a mobbing group which I observed following the onset of shriek calling supports the hypothesis of a recruitment function, however visual cues such as the sight of circling and diving swallows, or of the predator itself, are also likely to be important. High rates of shriek calling sustained 


\begin{tabular}{|c|c|c|c|c|c|c|}
\hline & $\begin{array}{c}\text { Shrieks } \\
\text { (calls/min) }\end{array}$ & $\begin{array}{c}\text { Tiks } \\
\text { (calls/min) }\end{array}$ & $\begin{array}{c}\text { Rasps } \\
\text { (calls/min) }\end{array}$ & $\begin{array}{c}\text { Dives } \\
\text { (dives } / \mathrm{min} \text { ) }\end{array}$ & $\begin{array}{c}\text { Swallows } \\
\text { Present }\end{array}$ \\
\hline \multirow{6}{*}{ 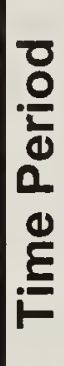 } & $0-30 \mathrm{~s}$ & 86.3 & 8.5 & 5.6 & 14.5 & 4.9 \\
\hline & $30-60 \mathrm{~s}$ & 120.1 & 9.6 & 10.3 & 18.8 & 5.3 \\
\hline & $60-90 \mathrm{~s}$ & 115.0 & 7.9 & 11.5 & 19.8 & 5.2 \\
\hline & $90-120 \mathrm{~s}$ & 115.3 & 9.2 & 10.2 & 18.7 & 5.4 \\
\hline & $120-150 \mathrm{~s}$ & 110.3 & 9.2 & 10.4 & 18.9 & 5.0 \\
\hline & $150-180 \mathrm{~s}$ & 118.6 & 7.2 & 9.5 & 17.6 & 5.5 \\
\hline \multirow{4}{*}{\multicolumn{2}{|c|}{$\begin{array}{l}\text { Minimum } \\
\text { Maximum } \\
\text { Mean* } \\
S D\end{array}$}} & 0 & 0 & 0 & 0 & 0 \\
\hline & & 336 & 74 & 50 & 78 & 18 \\
\hline & & 116.2 & 8.7 & 10.4 & 18.8 & 5.2 \\
\hline & & 91.8 & 10.0 & 12.1 & 15.6 & 3.3 \\
\hline
\end{tabular}

Table 1. Change in response variables over the course of a 3-minute mobbing trial. Values shown are means (averages) for each 30-second segment. Overall means are calculated excluding the first 30-second segment of each trial (see text).

throughout the mobbing event (Table 1) may be important for maintaining attendance as well as enhancing the overall sensory stimulus delivered by the mobbing group to the predator.

Tiks and rasps have traditionally been lumped together in terms of function, however differences in their form and use suggest that their functions may be different. ${ }^{4}$ The placement of the rasp call at the bottom of the dive suggests that it may serve as an aggressive auditory attack on the predator that may be important to startle it and get it to "move on".' The use of tiks during both circling and diving suggests that their function is not uniquely a sensory attack on the predator, and tiks may in fact be contributing more to confusing the predator by drawing its attention to many circling individuals. ${ }^{1}$ In the context of diving, tiks during the descent may be important in drawing the attention of the predator to the incoming stimulus of a swooping swallow since contact is rarely made. These functional distinctions remain speculative, however, and future work examining the behaviour of predators being mobbed would do much to clarify the roles of different aggression calls in the mobbing context.

\section{Acknowledgements}

I thank Don Kramer and Bob Clark for their excellent supervision and for comments on an earlier version of the manuscript, the Canadian Wildlife Service for use of the NWA and equipment, Ian Shirley for use of video equipment, Thierry Deux for help in the field, and Dennilyn Parker and her ferret Hobo for their amiable cooperation.

1. CURIO, E. 1978. The adaptive significance of avian mobbing: I. Teleonomic hypotheses and predictions. Zeitschrift für Tierpsychologie 48: 175-183.

2. FICKEN, M. S. and J. POPP. 1996. A comparative analysis of passerine mobbing calls. Auk 113(2): 370380 .

3. ROBERTSON, R. J., B. J. STUTCHBURY and R. R. COHEN. 1992. Tree Swallow. In: Birds of North America. (Poole, A.F., P. Stettenheim, and F.B. Gill, eds). No 11. American Ornithologists Union and Academy of Natural Sciences of Philadelphia, Washington DC and Philadelphia PA.

4. SHARMAN, M. Y., R. J. ROBERTSON and L. M. RATCLIFFE. 1994. Vocalizations of the tree swallow (Tachycineta bicolour) during the prelaying period: a structural and contextual analysis. American Midland Naturalist 132(2): 264-274.

5. SHIELDS, W. M. 1984. Barn swallow mobbing: selfdefence, collateral kin defence, group defence, or parental care? Animal Behaviour 32:132-148.

6. WINKLER, D. W. 1992. Causes and consequences of variation in parental defence behaviour by tree swallows. Condor 94:502-520.

7. WINKLER, D. W. 1994. Anti-predator defence by neighbours as a responsive amplifier of parental defence in tree swallows. Animal Behaviour 47:595-605. 